\title{
A BRIEF DISCUSSION OF THE EMPIRICAL PLAUSIBILITY OF THE REFLECTIVE EPISTEMIC AGENCY
}

\author{
Ana Margarete Barbosa de Freitas ${ }^{1}$ \\ Felipe Rocha Lima Santos ${ }^{2}$
}

\begin{abstract}
This paper aims to discuss one specific feature of Sosa's performance epistemology, which is what we call Reflective Epistemic Agency. We argue that Sosa defends a problematic version of epistemic agency on its reflective level. We contrast Sosa's idea of reflective epistemic agency with Proust's theory of metacognition to argue that the argument in favor of Reflective Epistemic Agency may lack some empirical plausibility, thus, it should be either revised or abandoned.
\end{abstract}

Keywords: Virtue Epistemology. Performance Epistemology. Epistemic Agency.

\section{INTRODUCTION}

Ernest Sosa's Virtue Epistemology, as a reliabilist theory of knowledge, places the subject's intellectual virtues or cognitive competences as the center of epistemic evaluations. The agent's epistemic performances are subject to normative evaluations, just like any other human activity that aims at any objective. The evaluative model of performances, according to Sosa, is represented by the $A A A$ structure (Accuracy, Adroitness, Aptness). Thus, the performance-based approach considers that the normativity involved in epistemic evaluation has the same evaluative structure as athletic, musical, artistic, or any other human activity. As Sosa describes:

\footnotetext{
${ }^{1}$ Federal University of Bahia (UFBA), Salvador, BA - Brazil. 1 https://orcid.org/0000-0003-05053593 E-mail: anamargarete11@yahoo.com.br

2 Federal University of Bahia (UFBA), Salvador, BA - Brazil. Pesquisador PNPD/CAPES. $\mathrm{https} / /$ orcid.org/0000-0001-9319-9538 E-mail: frls.ba@gmail.com

https://doi.org/10.1590/0101-3173.2021.v44dossier2.12.p173
}

This is an open-access article distributed under the terms of the Creative Commons Attribution License. 
Belief is a kind of performance, which attains one level of success if it is true (or accurate), a second level if it is competent (or adroit), and a third if its truth manifests the believer's competence (i.e., if it is apt). Knowledge on one level (the animal level) is apt belief. The epistemic normativity constitutive of such knowledge is thus a kind of performance normativity. (SOSA, 2011, p. 1).

It can be said that knowledge is thus understood as the expression of cognitive achievement, a cognitive performance so that the action of a virtuous agent in the cognitive domain becomes essential to achieve knowledge reliably.

Although Sosa $(2009 ; 2011 ; 2015)$ considers that knowledge is a cognitive achievement that develops at various levels - Animal, Reflective, and Full, he highlights reflective knowledge as the highest epistemic achievement and full aptness as the most desirable stage for cognitive performances. Reflective knowledge reaches a level of knowledge higher than mere animal knowledge, as the agent can have a perspective on the source of his beliefs and defend the reliability of those sources, in addition to manifesting freedom of choice and control over beliefs. Reflective knowledge is based on an introspective type of justification concerning the aptness of the belief given the agent's epistemic perspective; a kind of justification that animal knowledge cannot provide. Still, according to Sosa $(2009 ; 2011)$, it is only when agents reach reflective knowledge that they present the highest, most reliable, and apt form of knowledge.

Animal knowledge, although extremely useful, falls far short of distinctly human capacities, so that the hallmark of human knowledge and epistemic agency is reflective knowledge, as it more fully manifests the rational nature and human capacity to respond for its actions. And this type of knowledge is more valuable because it is something that the agent consciously and deliberately performs in the epistemic domain, which makes reflection a necessary condition for the constitution of the epistemic agency.

It is important to emphasize that the notion of epistemic agency in Sosa is, therefore, related to the highest levels of human performances that involve reflection, self-awareness, and full aptness. Sosa recognizes that there are three distinct categories of representational states or performances in the human species: a purely functional state, a hybrid, and the (full) agency, the latter being what interests us in this paper. He describes these three states as follows: 
(a) the merely functional, of a sort not at all penetrable or affectable through agential control; (b) the fully agential, of a sort directly penetrable or affectable through such control; and (c) hybrid representational states, of a sort affectable through such control, but only indirectly. (SOSA, 2015, p. 93).

Thus, we can define the notion of Reflective Epistemic Agency defended by Sosa as follows:

[R-EAg] Reflective, self-conscious, and directly controlled action that enables the agent to make judgments, decide what to believe, recognize the reliability of the process of forming her beliefs and defend her epistemic perspective.

This notion of epistemic agency involves direct agency, exercised at the highest epistemic level through our reflexive capacity. In this way, when we reflect, our beliefs are typically formed through a deliberative process that comprises an ability to choose the course of the judgment, which allows us to exercise control over it. It, therefore, seems correct to say that according to Sosa, epistemic agency is related to the idea that human beings are active in the exercise of their judgments, which implies freedom of action and epistemic freedom about beliefs.

This brief presentation serves to demonstrate that Sosa's performance epistemology has as its center of analysis the epistemic agent and his performance at the most diverse levels, especially at the level of the reflexive epistemic agency. Due to his theoretical innovations, without a doubt, Sosa is one of the most important philosophers for contemporary epistemology. However, this does not imply that his theory has no problems, some perhaps possibly related to the central theses of his theory. One of these problems directly concerns the empirical plausibility of his theory, mainly about the notion of epistemic agency and the role of reflection in satisfying epistemic objectives.

In this sense, an important criticism concerns what Sosa calls metaaptness - the ability to assess one's own first-order beliefs. Philosophical studies focused on the area of metacognition - the ability to think about one's own thinking or to monitor and control one's cognitive activity - have shown 
that, unlike what Sosa claims, metacognition is a natural type that has a set of functional characteristics independent of those associated with the selfattribution of mental states - and that during metacognitive activity, rational thoughts are not available to instruct a thinker about what she can believe in and thus allow her to be responsible for her mental agency (PROUST $2010 ; 2013)$. These arguments challenge the image of the epistemic agent as defended by Sosa and reflect on the normative character of human actions in the epistemic domain, directly questioning the notion of epistemic agency and the role of reflection in satisfying epistemic objectives.

Thus, this article aims to present the exclusivist/externalist approach to metacognition as advocated by Joëlle Proust $(2010$; 2013) and the repercussions of that approach for Ernest Sosa's Performance Epistemology.

\section{THE EXCLUSIVIST/EXTERNALIST APPROACH TO METACOGNITION}

In her work on the Philosophy of Metacognition, Joëlle Proust $(2008 ; 2010 ; 2013)$ usually defends an exclusivistlexternalist perspective of metacognition - as an exclusive capacity for self-assessment of ones own thinking that is especially related to ones own skills and his evaluation, being that at least part of such an assessment is conducted without any particular theoretical knowledge of the mind - against an inclusivist/internalist view of metacognition - such as the ability to attribute mental states to oneself or others, making evaluative episodes a special case of this general capacity.

Proust (2013) believes that theoretical considerations derived from studies on human development, human learning and the evolution of the species leave no room to defend internalist positions about metacognition. In her view, the widespread assumption of internalist positions that

[...] the mechanisms that serve a given function - say, epistemic decision should directly reflect our way of expressing that function verbally, as what it is rational to do or think, given one's antecedent mental states. [...] Just as logical or probabilistic reasoning turns out to rely on heuristics that have little to do with the science of logic and probability theory, metacognition might well rely on heuristics that do not need to involve the propositional knowledge one has of one's mental contents. (PROUST, 2013, p. 1-2).

Metacognitive internists understand that to monitor or endorse their own mental dispositions, subjects must form beliefs about their propositional 
attitudes and their associated contents so that the monitoring of mental states is a causal consequence of the knowledge of their own mental contents. Proust $(2010 ; 2013)$ calls this concept the Inclusivist Definition because it implies the inclusion of the ability to attribute mental states to oneself or others as a condition for the possibility of carrying out cognitive assessments. Metacognitive skills, seen in this way, motivate epistemic internalism, the view that the agent must be able to justify her own beliefs, presenting reasons for her doxastic attitudes based on his epistemic skills and cognitive resources, such as introspection.

It is possible here to make a relationship between the Inclusivist Definition of metacognition and Sosa's perspective on reflective knowledge a distinctly human epistemic achievement and higher than animal knowledge, as it allows the subject to "[...] answer that one does know or that one is epistemically justified, and [...] to defend this through the reliability of one's relevant faculties". (SOSA, 2009, p. 153). ${ }^{3}$

Sosa usually associates reflection with the capacity for deliberative control over first-order beliefs, to put these beliefs under reflective scrutiny, judging them and freely choosing what to believe, thus forming second-order beliefs. The processes that form reflexive beliefs are thus different from the processes that form unreflective beliefs, since the latter are formed automatically and unconsciously, not being the product of the individual's agency. Thus, it seems that Sosa's conception of the role of reflection in satisfying epistemic objectives involves much of the Inclusivist Definition of metacognition since he considers reflection to be a controlled and self-conscious evaluative performance that analyzes and monitors the risk of failure or success in first-order, in addition to being associated with a second-order perspective on beliefs and cognitive processes, giving the individual introspective and privileged access to their beliefs, which allows them to defend them reliably (see R-EAg).

Although Proust rarely cites Sosa in her book Philosophy of Metacognition (2013), when she refers to virtue epistemologists she alludes to Sosa's Virtue Epistemology, more specifically to his book A Virtue Epistemology: Apt Belief and Reflective Knowledge (2007), and states that for these

\footnotetext{
${ }^{3}$ Although Sosa defends a reliabilism epistemological perspective for knowledge, in his epistemological project there are many references to internalist intuitions, so the most correct would be to say that he defends a position that tries to make internalist and externalist positions about knowledge compatible.
} 
[...] a mental agent should be able not only to evaluate the outcomes of her mental actions, but also to consciously recognize that her ability to recognize epistemic norms is crucially involved in these actions. Mental agency, on this reading, involves an ability to take explicit responsibility for one's mental performances. Confidence is seen as resulting from a judgement about one's own cognitive competence. Non-humans have to be denied access to this rich form of self-understanding, which belongs to analytic metacognition. (PROUST, 2013, p. 303).

In fact, Sosa (2015) does not deny that we routinely produce more animal knowledge than reflective knowledge. However, he states that the rational orientation involved in reflective judgments helps us to improve and manage our skills, to avoid certain situations, and to have a coherent perspective and explanatory of the reliability of the sources of our beliefs, in addition to being the region of freedom where the deontic framework is most clearly applicable and where we can exercise our epistemic agency. Because of this, it is considered a better, more reliable, desirable, and sensitive knowledge of the first-order factors, allowing the agent the possibility of believing, disbelieving, or suspending the judgment, the latter attitude being possible only due to second-order mental actions.

Proust (2013), notably, disagrees with the Inclusivist Definition about metacognition and, consequently, also disagree with Sosa's intuitions about reflective knowledge, the role of reflection, and the concept of epistemic agency. She defends an Exclusivist Definition of metacognition that, based on an externalist position, analyzes metacognition as a natural type, as a set of processes whose function is exclusively to monitor or regulate cognitive or mental actions, that is, as a competence for self-assessment based on, in part, in non-analytical knowledge, with procedural characteristics. The Exclusivist conception of metacognition is supported by three main claims: i) "mental and ordinary actions do not have the same basic normative structure" (PROUST, 2013 , p. 5); ii) "metacognition, understood as a self-assessment of one's own predicted or acquired mental properties, is a constitutive ingredient of every mental action, but is absent from ordinary basic actions" (PROUST, 2013, p. 5); and iii) "this ability is not unique to humans" (PROUST, 2013, p. 5). We will now focus on the argument that metacognition is not an exclusive skill of human beings. ${ }^{4}$

\footnotetext{
${ }^{4}$ In this article, we will focus on the analysis of statement (iii), for a more in-depth debate on the other statements see Freitas (2019).
} 


\section{MetaCogNition IS NOT AN EXCLUSIVE ABILITY OF HUMAN BEINGS}

According to Proust (2013), many non-human animals can act mentally, they are efficient in remembering and assessing their reliability in carrying out their tasks. This leads us to believe that the ability to conceptually represent one's first-order attitudes cannot be a necessary condition for the development of metacognitive competence.

Contrary to Sosa's idea (2009) that only humans are capable of metaaptness - that is, to analyze their first-order competence and their environment, assessing the risk of failure or success in its execution, through their reflective skills -, Proust $(2008 ; 2013)$ argues that metacognitive interventions do not imply "knowing reflexively". When a subject engages in mental action, metacognition acts through the self-probing process - which assesses the likelihood that he will be able to successfully perform the mental action (to remember $r$, to learn $p$, to account $q$, etc.) -, and post-evaluation - which assesses the accuracy of informational retrieval -, and this does not imply that the subject reflexively knows that she is carrying out these operations, as these processes evaluate success in a modular, strictly closed manner and do not use - or at least do not need to use - a rich conceptual framework for making inferences and generalizations from this assessment. The reason for this statement is that children and non-human animals, who cannot attribute mental states to themselves, have been found to perform metacognitive tasks correctly.

Evidence extracted from Comparative Psychology (SMITH et al, 2003; SMITH, 2005) suggests that non-human animals, such as monkeys and dolphins, can adequately assess their level of self-confidence in tasks related to perception and memory, in which they can answer yes, not or uncertain. The results demonstrate that they seem to make rational decisions based on these assessments, as it was observed that when the target stimulus is difficult to discriminate perceptually or to remember, the animals choose not to offer an answer if such a choice is offered to them, and its reliability increases as they are free to respond or not. This means that some non-human animals are able to recognize epistemic norms, even in the absence of mental concepts and reflective awareness, that is, procedural metacognition occurs at a subpersonal level without the need for meta-representation.

According to Proust (2013), the most plausible answer to the sensitivity to epistemic norms presented by both children and non-human animals and by 
adult humans can be found in the affective states: "A feeling 'tells' a subject, in a practical, unarticulated, embodied way, how a given mental act is developing concerning its constitutive norm, without needing to be reflectively available to the believer" (PROUST, 2013, p. 158). This statement contradicts Sosa's $(2009 ; 2015)$ claim that sensitivity to epistemic norms depends, primarily, on the agent's ability to consciously control her cognitive results, which makes her distinguish animal knowledge from reflective knowledge, the latter distinctly human and therefore more reliable.

According to Proust (2013), sensitivity to epistemic norms is tracked by epistemic feelings, that is, conscious noetic feelings that are generated by inferential heuristics that operate implicitly and unintentionally. Examples of epistemic feelings are the feelings of knowledge, the feeling of fluency, the "tip of the tongue" phenomena, the feelings of uncertainty, the insight, the feeling of being lost, among others.

Epistemic feelings constitute the "representational format underlying procedural metacognition" (PROUST, 2013, p. 158) and are identified as an authoritative source of non-conceptual information ${ }^{5}$ to acquire true beliefs; they "might result from comparators that do not seem to belong to propositional ways of representing facts" (PROUST, 2013, p. 111). When a subject performs a mental action - remember that $p$, for example - selfprobing is made possible by the person's feelings about this task, it is these subjective feelings that safely track the cognitive adequacy of the subsequent mental action - a feeling that it is possible to carry out the action; likewise, in the post-evaluation, it is the epistemic feelings that safely track objective truth or the correction of mental action - a feeling about the certainty that $p$. In this way, feelings carry subpersonal epistemic information, they act on procedural metacognition, helping to control and monitor subjective uncertainty, and the subject does not have conscious access to how she arrived at these results, she just feels that it is so and acts based on this information ${ }^{6}$. According to Proust (2013, p. 146), noetic feelings

\footnotetext{
${ }^{5}$ Not all philosophers accept the existence of non-conceptual content. There is a great debate with different views on the role of concepts in the content, for further details on this topic see Cussins (1990), McDowell (1994), Peacocke (2001), Bermúdez (2003).

${ }^{6}$ In adult humans, "noetic feelings are offering a rational transition to the acquisition of concepts related to knowledge, and of epistemic modals, that is, modes of knowing, such as doubts, certainties, and guesses." (PROUST, 2013, p. 140). According to Burton (2008), in some situations, the feeling of knowing arising from epistemic feelings is felt as a thought generated from elements in a correct line of reasoning.
} 
[...] carry defeasible information about people's normative sensitivity to cognitive success of the current performance. This association between fact and norm is a property of every normative behavior. A descriptive fact has been selected (by evolution, by learning?) as being relevant to norm-sensitivity because, first, it actually predicts epistemic success, and, second, because it provides access to cues that agents can use for normatively controlling their actions. This view is thus an expressivist view about epistemic norms: agents initially use their feelings (and their rich nonconceptual contents) to evaluate their performance in a norm-sensitive way. Felt fluency, furthermore, motivates agents to act in a norm-directed way. Normative work, however, occurs 'behind the scenes', through the recalibration mechanisms that allow a system to realign its own sensitivity on the objective trials of prior performances.

However, Proust (2013) points out that these epistemic feelings are not strictly subjective, on the contrary, they are calibrated by external social and physical restrictions, that is, by the history of the individual's previous results about her mental actions. This means that "the existence and reliability of epistemic feelings supervene in part on the existence and quality of the feedback provided" (PROUST, 2013, p. 200). So epistemic feelings are not necessarily accurate, they can be illusory, leading the individual to make irrational decisions about how to act mentally, if exposed to inadequate feedbacks.

Thus, different from the position defended by Sosa (2009; 2011; 2015) - that meta-aptness, that is, reflexive self-assessment of first-order beliefs, is a distinctly human virtue achieved self-consciously and deliberately -, Proust $(2008 ; 2013)$ supports a perspective that understands metacognition as a procedural skill found in both humans and non-human animals. This ability occurs without the need for conceptual content, being performed at a subpersonal level, so that it does not depend on the individuals' introspective capacities, such as direct control and conscious access. Sensitivity to epistemic norms (truth, intelligibility, coherence, etc.) results from epistemic feelings that operate from a cognitive architecture that is shaped by the dynamic environment in which the individual is opaque, that is, without her being aware and control of the facts that influence her, leaving her only to trust these feelings to evaluate the viability of his mental actions. 


\section{ConClusion}

As we can see, Proust's arguments go against Sosa's epistemological project, mainly, to his statements that concern human reflexive capacities and the concept of epistemic agency (R-EAg). While Sosa defends that human beings can directly control the performance of their judgments and make decisions deliberately, with transparent access to their epistemic perspective, the empirical results show that the mechanisms responsible for epistemic assessments, including reflective processes, are not available on a personal level, but it's available on a subpersonal level, where it is not possible to have direct control and conscious access, which contradicts to the normative and agency statements defended by Sosa's Performance Epistemology.

Because it lacks empirical plausibility, Sosa’s epistemological project seems to fail to attempt to place the agent at the center of normative epistemic analysis - by comparing cognitive knowledge-producing performances to ordinary practical actions that outline self-awareness and voluntary control; thus, it cannot offer an adequate response to the role of the cognitive agent in satisfying epistemic objectives.

FREITAS, A. M. B.; SANTOS, F. R. L. Uma breve discussão sobre a plausibilidade empírica da agência epistêmica reflexiva. Trans/form/ação, Marília, v. 44, p. 173-184, Edição Especial - Dossier "Ernest Sosa”, 2021.

Resumo: Este artigo visa discutir uma característica específica da epistemologia do desempenho de Sosa, que é o que chamamos Agência Epistêmica Reflexiva. Argumentamos que Sosa defende uma versão problemática da agência epistêmica no seu nível reflexivo. Contrastamos a ideia de Sosa de agência epistêmica reflexiva com a teoria da metacogniçáo de Proust para argumentar que o argumento a favor da Agência Epistêmica Reflexiva pode carecer de alguma plausibilidade empírica, pelo que deve ser revisto ou abandonado.

Palavras-chave: Virtude Epistemológica. Performance Epistemológica. Agência Epistêmica. 


\section{REFERENCES}

BERMÚDEZ, J. L. Thinking Without Words. New York: Oxford University Press, 2003.

BURTON, R. On Being Certain: Believing You Are Right Even When You're Not. New York: St. Martin’s Griffin, 2008.

CUSSINS, A. The connectionist construction of concepts. In: Biden, M. (Ed.) The Philosophy of Artificial Intelligence. Oxford: Oxford University Press, 1990, p. 380400.

FREITAS, A. Agência Epistêmica, Naturalismo e Normatividade. Perspectiva Filosófica, v. 46, n. 2, p. 71-115, 2019.

McDOWELL, J. The content of perceptual experience, The Philosophical Quarterly, v. 44, n. 175, p. 190-205, 1994.

PEACOCKE, C. Does perception have a nonconceptual content? The Journal of Philosophy, v. 98, n. 5, p. 239-64, 2001.

PROUST, J. Epistemic Agency and Metacognition: An Externalist View. Proceedings of the Aristotelian Society, v. 108, p. 241-268, 2008.

PROUST, J. Metacognition. Philosophy Compass, v. 11, n. 5, p. 989-998, 2010.

PROUST, J. The Philosophy of Metacognition: mental agency and self-awareness. Oxford: Oxford University Press, 2013.

SMITH J. Studies of uncertainty monitoring and metacognition in animals and humans. In Terrace, H. S.; Metcalfe, J. (Eds.). The Missing Link in Cognition: Origins of Selfreflective Consciousness. New York: Oxford University Press, p. 242-271, 2005.

SMITH, J.; SHIELDS, W.; WASHBURN, D. The comparative psychology of uncertainty monitoring and metacognition. Behavioral and Brain Sciences, v. 26, Ed. 3, p. 317-339, 2003.

SOSA, E. A Virtue Epistemology: apt belief and reflective knowledge, Vol I. Oxford: Oxford University Press, 2007.

SOSA, E. Reflective Knowledge: apt belief and reflective knowledge, Vol. II. Oxford: Oxford University Press, 2009.

SOSA, E. Knowing Full Well. Princeton: Princeton University Press, 2011.

SOSA, E. Judgment and Agency. Oxford: Oxford University Press, 2015.

Received: 22/9/2020

Approved: 05/3/2021 
FREITAS, A. M. B.; SANTOS, F. R. L. 